\title{
SİNOP VE YÖRESİ AĞIZLARINDA HAYVAN ADLARI*
}

\section{Ergün ACAR*}

\section{Özet:}

Sinop ilinin dağlık ve engebeli fiziki yapısı çeşitli yabani hayvanların barınmasına olanak sağlarken ilin deniz kıyısında yer alması deniz hayvanlarının tanınmasını da sağlamıştır. Ayrıca ihtiyaç, beslenme ve ekonomik nedenlerle bölgede besi hayvancılığı gelişmiştir. Yöre halkının hayatında önemli bir yeri olan bu hayvanların adlandırılması oldukça dikkat çekicidir. Bu çalışmada kendi saha derlemelerimiz ve yazılı kaynaklardan tespit edilen 216 hayvan adı, türlerine göre tasnif edilerek ortaya konulmuştur. Böylece Sinop ve yöresinde zengin bir çeşitlilik gösteren hayvan adlarının önemine dikkat çekilmek istenmiştir.

Anahtar Kelimeler: Sinop ve yöresi, Hayvan Adları, Sinop Ağızları, Söz Varlığı

\section{Animal Names in Sinop and it's Dialects}

\begin{abstract}
:
As the mountainous and rugged physical condition of Sinop province has provided shelter for wild animals, the location of the province at the seaside has provided marine animals to be recognized. In addition, with economical and nutritional reasons fattening has improved. Naming of these animals which have an important place in the lives of locals is quite striking. In this study, 216 animal names which were derived through field work and written documents were put forth by their categories and kinds. By this way, attention to animal names which show a prosperous variety in Sinop was tried to be captured.

Keywords: Sinop and its Surrounding, Animal Names, Dialects of Sinop, Vocabulary

* Bu makale 4-7 Şubat 2016 tarihinde Barselona-İspanya Casa Convalescéncia'da düzenlenen "Uluslararası Sosyal ve Beşeri Bilimler Konferansı"nda sunulan bildirinin yeniden gözden geçirilmiş ve genişletilmiş halidir

* Yrd. Doç. Dr. Sinop Unniversitesi, Fen Edebiyat Fakültesi, Yeni Türk Dili Anabilim Dalı, eacar@sinop.edu.tr
\end{abstract}




\section{Giriş}

Ağız sözlüğü, bir yöreye ait standart yazı dilinde olmayan sözcükler ile anlamı ve fonetiği farklı eşzamanlı sözcüklerin oluşturduğu söz varlı̆̆ıdır. Sinop ve çevresinin dağlık, engebeli fiziki yapısı ve kuzey sınırının denize kıyı olması yörede çeşitli kara ve deniz hayvanlarının yaşayıp tanınmasına imkân sağlamıştır. Bu durum köylerde ve kırsal kesimlerde yaşayan yöre halkının onlarla iç içe yaşam sürmesine ve karş11ıklı mücadelesine sebep olmuştur. İnsanlar onlardan; gıda, giyim, nakliye, güvenlik ve iktisadi gereksinimleri için faydalanmışlardır. Yöre halkının hayatında önemli bir yer edinen bu hayvanların adlandırılması da dikkat çekici bir zenginliğe sahiptir. Sinop ve Yöresi Ağızlarında varyantlarıyla beraber 216 adet hayvan adı tespit edilmiştir. Tespit edilen hayvan adları şunlardır: adı denmez, aker, akger, akyaveş, alabaş, alankese, alkara kılçık, anaç, aprak, as, asgelin, aru guşu, azmantıl, azulat, badl, bağarcık, bakal, balak(I), balak(II), belemüt, bınak, biçik, bişi, bosdili, böcek, böğ̈̈rye, bökelek, buzana, bürükcü, canavar, celep, cıcık, cı̆̆la bakall, cındak, cırık, cibin, cimin, circir, civirci, cozbakal, culk, culuk, cundak, cücü, cücük, çıngirye, çaça, çarpan, çarşak, çebiş, çeli, çepilek, çetik, çıyan, çökelez, çötük, çuluk, danadışl, dırık, duvaç, ebeç, elik, enik, erkeç, eşek añırtlă̆l, ferik, fitık, filik, gartgart, gaza, gebelek, gece guşu, gelincik, gelinkadın, gelō, geme, genek, gevur balığı, gıdl, gılavuz, gıraça, gızantak, gocaoğlan, godak(I), godak(II), godak(III), godu, göcen, göde, göden, gölbez, gölebice, gölük, gösen, gövürtya, guguk kuşu, gugukçu, guloğuz, guluguşu, gundak, gupay, gülük(I), gülük(II), gürüd, gürük, gürüsge, güyōn sineği, ibi, iskiri, istiridye, ivirya, hahor, hasgelin, hel, huma, humātun, kabaz, kāmiloğlan, kaplıkurba, kara bakal, kara kötek, kaşdelen, kestenkelek, kılă̆ız, kınık, kırık, kodak, korit, kölek, kömüş, köstenköpeği, köstüköpek, kuluç, kulun, küflü, külüskek, kürü, latin, malak(I), malak(II), mendek(I), mendek(II), menek, menük, mesek, minak, mincak, mındak, mini, murat kuşu, nallu fatma, okseyil, olaman, önük, öpelek, persi, pinpin, pirsi(I), pirsi(II), pirsik, pitı, porasak, porsak, porsuk, portak, potuk(I), potuk(II), potak(I), potak(II), potanak, pöçük, pörsü, purç, saça, sal, salyan, samır, sañsak, sargan, 
semle, seyis, sümüklü böcek, şaki, şibi(I), şibi(II), tarak, tarakçıl, teknelikurba, teknezligurbō, terempe, toklu, toruş, tosmak, töktök, tükmükçü, ustan, ürye, üveyik, vidik(I), vidik(II), viz, vizelek, yanuç, yapalak, yavrak, yavşak, yavşu, yavşuk, yeşilustan, yıldancı, yılarya, yılkı, yıllaç, yumak, yundu, yunducu.

Ağızlarda geçen bitki, hayvan, yer adları, lakaplar vs. gibi kavramlara verilen adlar, halkın ad vermedeki temel hareket noktasını belirlenmesi bakımından büyük önem taşır. Renkler, ad ve deyim aktarmaları, organ benzetmeleri hangi nedenlerden dolayı kullanılmaktadır? Bunların sosyolojik, psikolojik, ekonomik yapı ve ilişkilerinin ortaya çıkarılmasıyla bu adı verenlerin hayattaki öncelikleri, yaşam tarzları, hayata bakış açıları ortaya çıkacaktır. Yabancı kelimelerden geçen alıntıların uyarlamaları ise yörenin fonetik eğilimlerinin ortaya konması bakımından önemli veriler sağlayacaktır. Ayrıca bu adlandırmaların kullanım sıklığı ve kullanım alanları üzerinden yapılacak ağız atlasları bize çok değerli dil malzemeleri sunacaktır.

\section{HAYVAN ADLARI}

1. Genel İsimler: Bu tasnifte doğrudan hayvanlara verilen adlar değil de onların durumları ya da özellikleri hakkında yapılan genel adlandırmalara yer verilmiştir:

Çizelge 1: Hayvanlarla İlgili Genel Adlandırma Listesi

\begin{tabular}{|l|l|l|}
\hline Yöresel İsmi & Anlamı & Kaynak \\
\hline alabaş & Başı benekli hayvan & DS.173: Boyabat \\
\hline anaç & $\begin{array}{l}\text { Yaşını almış yavrusu olan kümes } \\
\text { hayvanı }\end{array}$ & DS.245: Sinop; MDD: Durağan \\
\hline azmantıl & Melez hayvan & SYS.13: Türkeli-Yeşiloba \\
\hline çarşak & Çarpık bacaklı hayvan & $\begin{array}{l}\text { MDD:Boyabat-Düzkaraağaç, } \\
\text { Dağtabaklı }\end{array}$ \\
\hline gızantak & $\begin{array}{l}\text { Çiftleşme arzusu duyan, kızışmış̧ } \\
\text { hayvan }\end{array}$ & MDD: Ayancık-Kayabaşı \\
\hline göklü & Gebe hayvan & DS.2138: Gerze ve köyleri \\
\hline gugukçu & İnatçı, hırçın hayvan & MDD: Boyabat-İsaoğlu \\
\hline
\end{tabular}




\begin{tabular}{|l|l|l|}
\hline kabaz & Boynuzsuz hayvan & SYS.58 \\
\hline toruş & Arabaya koşulan yedek hayvan & $\begin{array}{l}\text { DS.3970: Boyabat; MDD: Boya- } \\
\text { bat-Çurguşlar }\end{array}$ \\
\hline olaman & $\begin{array}{l}\text { Yaşına girmemiş koyun, keçi, inek } \\
\text { gibi hayvanların doğum yapması }\end{array}$ & MDD: Dikmen-Küçükkızık \\
\hline yıldancı & Her sene doğuran hayvan & SYS.197: Boyabat-Aşıklı, Çulhalı \\
\hline
\end{tabular}

2. Yabani Hayvanlar: Sinop, dağlik ve zengin bitki örtüsüne sahip bir ilimizdir.

Onun bu özelliği yabani hayvanların uygun yaşam alanlarına olanak sağlamıştır.

Sinop'ta oldukça fazla yabani hayvan yaşamakta olup, bu hayvanların adlandırılması da ilgi çekicidir. Adlandırmalarda; ad ve deyim aktarmaları, güzel adlandırma, arkaik unsurlar gibi pek çok etken söz konusudur.

Çizelge 2: Yabani Hayvan Adlarl Listesi

\begin{tabular}{|l|l|l|}
\hline Yöresel İsmi & Anlamı & Kaynak \\
\hline adı denmez & Sansar & MDD: Erfelek-Şerefiye \\
\hline alankese & Saksağan & DS.196: Gerze \\
\hline as & Gelincik & SYS.10: Boyabat-Çatpınar \\
\hline asgelin & Gelincik & SYS.10: Türkeli-Yeşiloba \\
\hline bağarcık & Kaplumbağa & DS.473: Sinop; SYS.56 \\
\hline balak (II) & Ayı yavrusu & SYS.16: Gerze-Kirençukuru \\
\hline böğürye & Deniz yengeci & MDD: Ayancık-Aliköy \\
\hline bişi & Yabani ördek & MDD: Sinop \\
\hline canavar & Domuz & MDD: Boyabat-Aşağıtabaklı \\
\hline çıngirye & Karides & SSD.4: Sinop \\
\hline çökelez & Sincap & $\begin{array}{l}\text { DS.1109: Boyabat; MDD: } \\
\text { Ayancık-Aliköy, Saraydüzü- } \\
\text { Aşağı Akpınar }\end{array}$ \\
\hline dırık & Sarı renkli bir sincap türü & MDD: Boyabat-Çatpınar \\
\hline duvaç & Ayı yavrusu & DS.1614: Sinop-Tıngır \\
\hline ebeç & Su kurbağası & $\begin{array}{l}\text { DS.1652: Ayancık; MDD: } \\
\text { Ayancık-Ortalık Dolamay Mah. }\end{array}$ \\
\hline elik & Dağ keçisi, ceylan & MDD.Boyabat \\
\cline { 2 - 3 } & &
\end{tabular}


Sinop Üniversitesi Sosyal Bilimler Dergisi, Cilt: I, Sayı: 1, Y11: Ocak-Haziran 2017

\begin{tabular}{|c|c|c|}
\hline eşek añırtlağı & Yengeç & MDD: Durağan-Kemerbahçe \\
\hline fitık & Domuz yavrusu & SYS.68: Boyabat-Aşıklı \\
\hline gaza & Karides & SSD.4: Gerze \\
\hline gelincik & Küçük etçil dağ hayvanı & MDD: Dikmen-Küçükkızık \\
\hline gelinkadın & Gelincik & $\begin{array}{l}\text { DS.1981: Sinop; SYS.77: Erfe- } \\
\text { lek-Şerefiye }\end{array}$ \\
\hline gelō & Büyük tarla faresi, geme & MDD: Türkeli-Çatakgüney \\
\hline geme & Fare & DS.1986: Sinop \\
\hline gocaoğlan & Ay1 & MDD: Boyabat-Aşıklı \\
\hline godak (II) & Domuz yavrusu & SYS.82: Erfelek-Kazmasökü \\
\hline göde & Kurbağa & MDD: Boyabat-Aşıklı \\
\hline göden & $\begin{array}{l}\text { Büyük, tombul, siyah renkli kara } \\
\text { kurbağası }\end{array}$ & MDD: Gerze-Abdaloğlu \\
\hline göcen & Tavşan yavrusu & $\begin{array}{l}\text { DS.2119: Boyabat; } \text { SYS.84: } \\
\text { Gerze-Kirençukuru }\end{array}$ \\
\hline gösen & Tavşan yavrusu & DS.2119: Boyabat \\
\hline hasgelin & Gelincik & MDD: Ayancık-Karakestane \\
\hline kaplıkurba & Kaplumbağa & MDD: Ayancık-Ortalık \\
\hline kestenkelek & Kertenkele & $\begin{array}{l}\text { MDD: Boyabat-Çatpınar Yalak } \\
\text { Mah., Durağan-Yeşilyurt }\end{array}$ \\
\hline köstenköpeği & Köstebek & MDD: Boyabat \\
\hline köstüköpek & Köstebek & MDD: Ayancık-Ortalık \\
\hline küflü & Deniz yengeci, pavurya & SSD.4: Sinop \\
\hline malak (II) & Ayı yavrusu & $\begin{array}{l}\text { SYS.129: Ayancık-Bakırlı; Tür- } \\
\text { keli-Çatakören }\end{array}$ \\
\hline mendek (I) & Tavşan yavrusu & DS.3160: Boyabat \\
\hline mesek & Domuz yavrusu & $\begin{array}{l}\text { DS.3171:Dikmen-Üçpınar; } \\
\text { SYS.133: Dikmen-Akçekese }\end{array}$ \\
\hline persi & Domuz yavrusu & DS.3432: Boyabat-Oğlakçılar \\
\hline pirsi (I) & Domuz yavrusu & SYS.151: Boyabat-Uzunçay \\
\hline pirsi (II) & Fare yavrusu & MDD: Ayancık-Aliköy \\
\hline pirsik & Domuz yavrusu & DS.3460: Ayancık-İnaltı \\
\hline pitık & Domuz yavrusu & DS.3448: Boyabat-Özek \\
\hline porasak & Domuz yavrusu & SYS.151: Sinop-Oğuzeli \\
\hline porsak & bk. porasak. & SYS.151: Gerze-Bolalı \\
\hline
\end{tabular}




\begin{tabular}{|l|l|l|}
\hline porsuk & bk.porasak. & SYS.151: Sinop-Sazlı \\
\hline portak & Domuz yavrusu & SYS.151: Türkeli-Çatakgüney \\
\hline potuk (I) & Ayı yavrusu & $\begin{array}{l}\text { DS.3474: Boyabat; SYS.151: } \\
\text { Dikmen-Kuzalan }\end{array}$ \\
\hline potuk (II) & Domuz yavrusu & $\begin{array}{l}\text { DS.3475: Gerze; SYS.151: Sa- } \\
\text { raydüzü-Yalmansaray }\end{array}$ \\
\hline potak (I) & Ayı yavrusu & SYS.151: Boyabat-Aşılı1 \\
\hline potak (II) & Domuz yavrusu & SYS.151: Boyabat-Çulhalı \\
\hline potanak & Domuz yavrusu & SYS.151: Dikmen-Bucak \\
\hline pörsü & Domuz yavrusu & $\begin{array}{l}\text { DS.3479:Erfelek-Kazmäökü; } \\
\text { SYS. 152: Ayancık-Bakırlı Balca } \\
\text { Mah. }\end{array}$ \\
\hline salyan & Yengeç & SSD.4: Sinop \\
\hline samır & Su sansarı & MDD: Boyabat-Akyörük \\
\hline teknelikurba & Kaplumbağa & MDD: Erfelek-Gümüşsuyu \\
\hline teknezligurbōo & Kaplumbağa & MDD: Erfelek-Balıfakı \\
\hline tosbağ & Kaplumbağa & DS.3971.Sinop \\
\hline ustan & Kertenkele & $\begin{array}{l}\text { SYS.60; } \\
\text { DS.4043: Ayancık-Düzköy }\end{array}$ \\
\hline yanuç & Yengeç & $\begin{array}{l}\text { DS.4175: Sinop ve çevresi; } \\
\text { MDD: Durağan-Kemerbahçe, } \\
\text { Boyabat-Çatpınar }\end{array}$ \\
\hline yavrak & Domuz yavrusu & $\begin{array}{l}\text { SYS.194: Boyabat-Akçakese } \\
\text { Garandun Mah. }\end{array}$ \\
\hline yeşilustan & Kertenkele & MDD: Durağan-Yeşilyurt \\
\hline yılkı & At sürüsü & DS.4271: Sinop \\
\hline & & \\
\hline
\end{tabular}

3. Balıklar: Sinop'un bir liman şehri olması ve kıyılarında çeşitli su ürünlerinin barınması ekonomik bakımdan balıkçılığın gelişmesine olanak sağlamıştır. $\mathrm{Bu}$ balık adlandırılmaları daha çok alıntı kelimelerin uyarlanmasıyla ya da öne çıkan özelliklerinin dikkate alınmasıyla yapılmıştır: 


\section{Çizelge 3: Balık Adları Listesi}

\begin{tabular}{|c|c|c|}
\hline Yöresel İsmi & Anlamı & Kaynak \\
\hline aker & Yılan balı̆̆g & SSD.4: Sinop \\
\hline belemüt & Palamut & SYS.19: Gerze \\
\hline çaça & $\begin{array}{l}\text { Hamsinin bol çıktığı sıralarda bulunan } \\
\text { bir cins balık }\end{array}$ & DS.839: Sinop \\
\hline çarpan & $\begin{array}{l}\text { Sirtı dikenli, büyüğü sarı, kırmızı, } \\
\text { küçüğü siyah renkte olan, çarptığında } \\
\text { eli ayağı kanatan iskorpit cinsinden } \\
\text { bir balık }\end{array}$ & DS. 1083: Sinop, SSD.4: Sinop \\
\hline gevur balığı & $\begin{array}{l}\text { Çayda yetişen yenmeyen bir balık } \\
\text { türü }\end{array}$ & SYS.78: Türkeli-Ayaz \\
\hline gıraça & Küçük istavrit balığı & MDD: Gerze \\
\hline gövürtya & Kaya balığ & SSD.4: Sinop \\
\hline iskiri & Kaya levreği & SSD.4: Sinop \\
\hline kara kötek & Eşkina balığı & SSD.4: Türkeli \\
\hline latin & Lapina balığ & SSD.4: Sinop \\
\hline okseyil & Sarkkulak kefal & SSD.4: Sinop \\
\hline saça & Kefalin küçük yavrusu & DS.3508: Sinop \\
\hline sargan & Zargana & DS.3543: Gerze, SSD.4: Sinop \\
\hline şaki & Yavru kalkan & SSD.4: Sinop \\
\hline tarak & İspari balığı, karagöz & SSD.4: Gerze \\
\hline tükmükçü & Horozbina balığı & SSD.4: Sinop \\
\hline yılarya & Kefal balığının küçüğü & DS.4266: Gerze \\
\hline
\end{tabular}

4. Evcil Hayvanlar: İnsanlar, besin ihtiyaçlarını karşılamak, ekonomik gelir elde etmek ve işlerinde güçlerinden faydalanmak üzere evcil hayvanlar beslemişlerdir. Yörede bu hayvanlara verilen adlandırmalar da oldukça zengindir:

\section{Çizelge 4: Evcil Hayvan Adları Listesi}

\begin{tabular}{|l|l|l|}
\hline Yöresel İsmi & Anlamı & Kaynak \\
\hline akger & Kırmızı renkli kıl keçisi & MDD: Durağan-Yassıalan \\
\hline alkara kılçı & Tiftik keçisi & MDD: Durağan-Yassıalan \\
\hline
\end{tabular}




\begin{tabular}{|c|c|c|}
\hline azulat & Aygır, at & SYS.13: Boyabat-Killik \\
\hline badı & Kaz & MDD: Boyabat \\
\hline balak (I) & Malak, manda yavrusu & $\begin{array}{l}\text { SYS.16: Dikmen-Çatak, Dura- } \\
\text { ğan-Yeşilyurt, Gerze-Yamacık }\end{array}$ \\
\hline bınak & Kedi yavrusu & SYS.22: Boyabat-Uzunçay \\
\hline biçik & Buzağ 1 & MDD: Boyabat \\
\hline bosdili & $\begin{array}{l}\text { Oğlak, keçi yavrusu, bir yaşında hay- } \\
\text { van }\end{array}$ & \begin{tabular}{|ll} 
SYS.24: & Durağan-Yeşilyurt, \\
Sarıar & \\
\end{tabular} \\
\hline celep & Dişi eşek & MDD: Türkeli-Ayaz \\
\hline cicık & Kümes hayvanlarının yavrusu, civciv & DS.1022: Boyabat \\
\hline condak & Kedi yavrusu & SYS.29: Durağan-Köklen \\
\hline culk & Kuluçkaya yatan tavuk & DS.1018: Boyabat \\
\hline culuk & Hindi & MDD: Boyabat \\
\hline cundak & Kedi yavrusu & MDD: Dikmen-Yumaklı \\
\hline cücü & Civciv & MDD: Boyabat \\
\hline cücük & Civciv & $\begin{array}{l}\text { DS.1022: Sinop; MDD: Dura- } \\
\text { ğan-Yeşilyurt, Dikmen-Kerim, } \\
\text { Gerze-Yamackk }\end{array}$ \\
\hline çebiş & Bir yaşındaki keçi yavrusu & DS.1099: Sinop \\
\hline çeli & Keçi yavrusu & DS.1122: Erfelek-Kazmasökü \\
\hline çepilek & Keçi yavrusu, oğlak & $\begin{array}{l}\text { MDD: Ayancık-Bakırlızaviye } \\
\text { Kuzdağı Mah. }\end{array}$ \\
\hline çetik & Kedi yavrusu & $\begin{array}{l}\text { SYS.41: Boyabat-Uzunçay, } \\
\text { Türkeli-Yeşiloba }\end{array}$ \\
\hline çötük & Kedi yavrusu & $\begin{array}{l}\text { SYS.46: Ayancık-Bakırlızaviye } \\
\text { Kuzdağı Mah. }\end{array}$ \\
\hline enik & Kedi ve köpek yavrusu & $\begin{array}{l}\text { DS. 1757: Sinop; SYS.62: Dik- } \\
\text { men-Kerim }\end{array}$ \\
\hline erkeç & $\begin{array}{l}\text { ÜÇ-dört yaşlarında enenmiş erkek } \\
\text { keçi }\end{array}$ & DS.1773: Sinop \\
\hline ferik & $\begin{array}{l}\text { Kümes } \\
\text { çıkmış yavrularıanlarının piliç }\end{array}$ & $\begin{array}{l}\text { DS.1846: Gerze, Boyabat; } \\
\text { SYS.67: Ayancık-Göldağ1 }\end{array}$ \\
\hline filik & Keçi yavrusu & DS.1865: Boyabat \\
\hline gidı & Dişi kuzu & MDD: Ayancık-Karakestane \\
\hline girık & Eşek yavrusu & MDD: Boyabat \\
\hline godak (I) & Eşek yavrusu & SYS.82: Ayancık-Göldağ \\
\hline godak (III) & Keçi yavrusu & SYS.82: Sinop-Dizdaroğlu \\
\hline
\end{tabular}


Sinop Üniversitesi Sosyal Bilimler Dergisi, Cilt: I, Sayı: 1, Y11: Ocak-Haziran 2017

\begin{tabular}{|c|c|c|}
\hline godu & Erkek hindi & MDD: Boyabat-Çatpınar \\
\hline gölbez & Köpek yavrusu & $\begin{array}{l}\text { DS.2140: Boyabat, Gerze; } \\
\text { SYS.85: Türkeli-Yeşiloba, } \\
\text { Erfelek-Kazmasökü, Ayancık }\end{array}$ \\
\hline gölük & $\begin{array}{l}\text { At, eşek, beygir, katır vb. yük taşıyan } \\
\text { ve binilen hayvan }\end{array}$ & $\begin{array}{l}\text { DS.2145: Boyabat; SYS.86: } \\
\text { Durağan-Çerçiler; Boyabat- } \\
\text { Yenice, Çukurhan }\end{array}$ \\
\hline gundak & Kedi yavrusu & $\begin{array}{l}\text { SYS.88:Saraydüzü-Yalmansaray, } \\
\text { Durağan-Yeşilyurt }\end{array}$ \\
\hline gupay & Av köpeği & SYS.88: Boyabat-Çaybaşı \\
\hline gülük (I) & Kedi yavrusu & SYS.90: Türkeli-Aydoğdu, Işıklı \\
\hline gülük (II) & Kuluçkaya yatan tavuk & SYS.90: Ayanc1k-Dibekli \\
\hline gürük & Civciv & MDD: Türkeli-Çatakgüney \\
\hline gürüsge & Civciv & MDD: Türkeli-Işıklı \\
\hline ibi & Hindi & MDD: Boyabat-Aşıklı \\
\hline kınık & Eşek yavrusu & SYS.117: Boyabat-Eğlence \\
\hline kodak & Eşek yavrusu, sipa & $\begin{array}{l}\text { DS. 2896: Sinop; } \\
\text { SYS.120: Gerze-Kirençukuru }\end{array}$ \\
\hline korit & Bir yaşına kadar olan erkek keçi & DS.2925: Gerze-Karlı \\
\hline kömüş & Manda & MDD: Boyabat \\
\hline kulun & At ve eşek yavrusu & DS.2997: Sinop \\
\hline külüskek & Kuluçkaya yatan tavuk & MDD: Dikmen-Kuzalan \\
\hline kürü & Eşek yavrusu, sıpa & DS.2822: Ayancık \\
\hline malak (I) & Manda yavrusu & $\begin{array}{l}\text { DS.3108: Sinop; SYS.129: Sa- } \\
\text { raydüzü-Aşağıakpınar }\end{array}$ \\
\hline mendek (II) & Kedi yavrusu & SYS.132: Boyabat-İsaoğlu \\
\hline mincak & Kedi yavrusu & SYS.134: Boyabat-Bengübelen \\
\hline mındak & Kedi yavrusu & $\begin{array}{l}\text { DS.3185: Boyabat; MDD: Bo- } \\
\text { yabat-Bengübelen }\end{array}$ \\
\hline menek & Kedi yavrusu & SYS.133: Gerze-Bolalı \\
\hline menük & Kedi yavrusu & DS.3165: Sinop-Korucuk \\
\hline minak & Kedi yavrusu & $\begin{array}{l}\text { DS.3185: Boyabat; SYS.133: } \\
\text { Boyabat-Ar1oğlu }\end{array}$ \\
\hline mini & Köpek yavrusu & MDD: Boyabat \\
\hline nallu fatma & Eşek & MDD: Ayancık-Aliköy \\
\hline önük & Kedi, köpek yavrusu & DS.3341: Boyabat \\
\hline
\end{tabular}




\begin{tabular}{|l|l|l|}
\hline pöçük & Keçi yavrusu & MDD: Boyabat-Aşılılı \\
\hline seyis & İki-üç yaşlarında enenmiş erkek keçi & $\begin{array}{l}\text { MDD: Boyabat-Hacıahmetli, } \\
\text { Saraydüzü-Aşağıakpınar }\end{array}$ \\
\hline şibi (I) & Ördek & DS.3775: Boyabat \\
\hline şibi (II) & Ördek yavrusu, kaz yavrusu & SYS.170: Boyabat-Esengazili \\
\hline toklu & Altı aylıkla bir yaş arasındaki kuzu & $\begin{array}{l}\text { DS.3948: Sinop; } \\
\text { MDD: Boyabat-Bengübelen }\end{array}$ \\
\hline tosmak & Genç, küçük manda & $\begin{array}{l}\text { DS. 3972: Boyabat; } \\
\text { MDD: Dikmen-Yumaklı }\end{array}$ \\
\hline töktök & Erkek hindi & MDD: Durağan-Yağbasan \\
\hline ürye & Dişi tay & DS.4072: Sinop \\
\hline vidik (I) & Köpek yavrusu & DS.4104: Boyabat köyleri \\
\hline vidik (II) & Kaz yavrusu & SYS.189 \\
\hline yumak & Ayı yavrusu & SYS.199: Boyabat-Kurusaray \\
\hline yundu & Güçlü, iri eşek & SYS.199: Durağan-Kemerbahçe \\
\hline yunducu & Başı̧boş köpek & SYS.199: Boyabat-Aşıklı \\
\hline
\end{tabular}

5. Böcekler: Yöre halkının yaşam alanlarına tesir eden zararlı böcekler de vardır. Bu hayvanların tespit edilen adları şunlardır:

Çizelge 5: Böcek Adları Listesi

\begin{tabular}{|l|l|l|}
\hline Yöresel İsmi & Anlamı & Kaynak \\
\hline akyaveş & Bit & DS.164: Boyabat \\
\hline çıan & Kırkayak & MDD: Boyabat-Çatpınar \\
\hline danadışı & Danaburnu böceği & MDD: Türkeli-Ayaz \\
\hline böcek & Bit & DS.754: Boyabat \\
\hline circir & Ağustos böceği & DS.926: Boyabat \\
\hline gebelek & Kelebek & MDD: Ayancık-Ortalık \\
\hline genek & Kene & $\begin{array}{l}\text { SYS.77: Türkeli-Kuzköy Yenice } \\
\text { Mah. }\end{array}$ \\
\hline gurud & Tahtakurusu & $\begin{array}{l}\text { SYS.89:Erfelek-Gökçebel, Balı- } \\
\text { fak1 }\end{array}$ \\
\hline gürüd & Tahtakurusu & MDD: Ayancık-Hatip \\
\hline istiridye & Deniz salyangozu & SSD.4: Sinop \\
\hline
\end{tabular}


Sinop Üniversitesi Sosyal Bilimler Dergisi, Cilt: I, Say1: 1, Y1l: Ocak-Haziran 2017

\begin{tabular}{|l|l|l|}
\hline kaşdelen & Danaburnu böceği & MDD: Boyabat-Alibeyli, Bağlıca \\
\hline yavşak & Bit yavrusu & DS.4206: Sinop \\
\hline yavşu & bk.yavşak. & SYS.194: Boyabat-Çeşnigir \\
\hline yavşuk & bk.yavşak. & SYS.194: Durağan-Gölalan \\
\hline öpelek & Kelebek & $\begin{array}{l}\text { SYS.144: Ayancık-Yarenler } \\
\text { Pelitçik Mah., Aliköy }\end{array}$ \\
\hline $\begin{array}{l}\text { sümüklü } \\
\text { böcek }\end{array}$ & Salyangoz & $\begin{array}{l}\text { MDD: Ayancık, Türkeli, Boya- } \\
\text { bat }\end{array}$ \\
\hline
\end{tabular}

6. Sinekler: Çift kanatlı eklembacaklardan olan sinekler, Sinop ve yöresinde daha çok büyükbaş hayvanları rahatsız eden türler için adlandırılmıştır:

Çizelge 6: Sinek Adları Listesi

\begin{tabular}{|c|c|c|}
\hline Yöresel İsmi & Anlamı & Kaynak \\
\hline bökelek & $\begin{array}{l}\text { Büyükbaş hayvanları rahatsız eden } \\
\text { bir çeşit sinek, gübre sineği }\end{array}$ & $\begin{array}{l}\text { DS.760: Sinop; SYS.24: Ayan- } \\
\text { cık-Aşağıöy, Boyabat-Arığlu }\end{array}$ \\
\hline buzana & Siyah, ince kanatlı, uçucu bir böcek & DS.810: Sinop \\
\hline cibin & Karasinek & DS.1202: Sinop \\
\hline cimin & Küçük sinek, tatarcık & $\begin{array}{l}\text { DS. 968: Sinop; SYS.32: Dura- } \\
\text { gan-Yeşilyurt }\end{array}$ \\
\hline güyōn sineği & $\begin{array}{l}\text { Yazın hayvanları sokarak dört nala } \\
\text { koşturan bir sinek cinsi }\end{array}$ & SYS.91:Boyabat-Gökçeağaçsakızı \\
\hline kölek & $\begin{array}{l}\text { Yazın, sıcakta hayvanların kanını } \\
\text { emen yeşil başlı büyük sinek }\end{array}$ & SYS.121: Boyabat-Dağtabaklı \\
\hline viz & bk.vizelek. & SYS.189: Türkeli-Ayaz \\
\hline vizelek & $\begin{array}{l}\text { Büyükbaş hayvanları 1sırarak rahatsız } \\
\text { eden bir sinek }\end{array}$ & $\begin{array}{l}\text { DS.4106: Boyabat; SYS.189: } \\
\text { Boyabat-Haciahmetli }\end{array}$ \\
\hline
\end{tabular}

7. Kuşlar: Sinop'un 1lıman iklim yapısı, yüksek ve alçak yüzey şekilleri pek çok yerleşik ve göçmen kuş türünün yaşamına olanak sağlamıştır. Lagün gölü özelliğindeki "Sarıkum gölü” su kuşları için oldukça elverişli ekolojik bir alandır. Bu alanda ve Sinop'un değişik yörelerinde tespit ettiğimiz yöresel kuş adları ise şunlardir: 


\section{Çizelge 7: Kuş Adları Listesi}

\begin{tabular}{|c|c|c|}
\hline Yöresel İsmi & Anlamı & Kaynak \\
\hline aprak & Güvercin & MDD: Boyabat-Akyörük \\
\hline aru kuşu & $\begin{array}{l}\text { Bal arılarını yiyerek geçinen, serçeden } \\
\text { az büyük, renkli bir kuş. Bağ bozumu } \\
\text { zamanı gelen göçmen bir kuştur }\end{array}$ & DS.318: Boyabat \\
\hline bakal & Karatavuk & $\begin{array}{l}\text { DS.490: Sinop; MDD: Erfelek- } \\
\text { Şerefiye }\end{array}$ \\
\hline bürükcü & Ormanda yaşayan bir çeşit kuş & DS.828: Sinop \\
\hline cığla bakalı & Renkli bir kuş türü & MDD: Türkeli-Ayaz \\
\hline cirık & Kuş yavrusu & SYS.30: Boyabat-Engilekin \\
\hline civirci & Bir kuş türü & MDD: Boyabat-Çatpınar \\
\hline cozbakal & Karatavuk & DS.1004: Sinop \\
\hline çuluk & Siyah bir kuş çeşidi & MDD: Durağan-Gölalan \\
\hline gartgart & Bir çeşit deniz kuşu & DS.1931: Sinop \\
\hline gece guşu & Baykuş & MDD: Erfelek-Balıfak1 \\
\hline gilavuz & Baykuş & $\begin{array}{l}\text { MDD: Ayancık-Ortalık Dolamay } \\
\text { Mah., Türkeli-Gökçealan }\end{array}$ \\
\hline gölebice & Su kuşu & MDD: Gerze \\
\hline guloğuz & Baykuş & $\begin{array}{l}\text { MDD: Türkeli-Gökçealan, Ak- } \\
\text { çabük }\end{array}$ \\
\hline guluguşu & Baykuş & MDD: Ayancık-Göldağ1 \\
\hline hahor & Baykuş & DS.2395: Gerze-Karlı \\
\hline hel & Doğan & MDD: Saraydüzü-Göynükören \\
\hline huma & Baykuş & MDD: Dikmen-Bucak \\
\hline humātun & Baykuş & MDD: Durağan-Aşağıalınca \\
\hline kara bakal & $\begin{array}{l}\text { Serçegillerden, eti için avlanan siyah } \\
\text { tüylü bir kuş, karatavuk }\end{array}$ & DS.2637: Sinop \\
\hline kılağız & Puhu kuşu & DS.2792: Ayancık-Ortaklık \\
\hline kuluç & Eğitilmiş atmaca & DS.2997: Sinop \\
\hline murat kuşu & Baykuş & MDD: Erfelek-Gümüşsuyu \\
\hline pinpin & İspinoz kuşu & DS.3456: Sinop \\
\hline purç & Bakal türü bir kuş & MDD: Ayancık-Aliköy \\
\hline sal & $\begin{array}{l}\text { Nevruzda ortaya çıkan kırmızı, uzun } \\
\text { kuyruklu bir kuş türü }\end{array}$ & MDD: Dikmen-Dudaş \\
\hline
\end{tabular}


Sinop Üniversitesi Sosyal Bilimler Dergisi, Cilt: I, Say1: 1, Y1l: Ocak-Haziran 2017

\begin{tabular}{|l|l|l|}
\hline sañsak & Saksağan kuşu & MDD: Boyabat-Dağtabaklı \\
\hline selme & $\begin{array}{l}\text { Saka gibi küçük kuşları tutmak için } \\
\text { alıştırılmış, sopa üstüne bağlanan avcı } \\
\text { kuş }\end{array}$ & DS.3577: Sinop \\
\hline tarakçıl & $\begin{array}{l}\text { Başında tarak biçiminde tüyleri olan } \\
\text { bir çeşit kuş }\end{array}$ & $\begin{array}{l}\text { DS.3831: Sinop; MDD: Ayan- } \\
\text { cık-Aliköy }\end{array}$ \\
\hline terempe & $\begin{array}{l}\text { Eğitilerek kuş avında kullanılan atma- } \\
\text { ca, doğan vb. avcı kuşlar }\end{array}$ & DS.3890: Sinop \\
\hline üveyik & Güvercine benzer göçmen bir kuştur & MDD: Ayancık-Aliköy \\
\hline yapalak & Baykuş & DS.4175: Gerze \\
\hline yıllaç & Y1lını doldurmuş saka vb. kafes kuşu & DS.4271: Sinop \\
\hline
\end{tabular}

\section{Sonuç}

Hayvan adları Türkçede oldukça zengin bir söz varlığına sahiptir. Bu çalışmayla Sinop ve yöresine ait sözlü ve yazılı kaynaklardan tespit edilen 216 hayvan adıyla Türkçenin söz varlığına katkı sunulmak amaçlanmıştır. Bu adlandırmalar hayvanlarla ilgili genel adlandırmalar, yabani hayvanlar, evcil hayvanlar, balıklar, böcekler, kuşlar ve sinekler olmak üzere yedi grupta tasnif edilmiştir. Bu adların kavramsal, anlamsal, onomatolojik ve dil dışı gerçeklik düzeyleri dikkate alındığında şöyle bir tasnif yapılabilir:

1. Renk adlarına dayalı adlandırmalar: alabaş, as, kara bakal, kara kötek, yeşilustan, ...

2. Başka hayvanlardan benzetilen adlandırmalar: aru kuşu, danadışı, teknelikurba,...

3. Büyük ya da küçüklüğüne göre yapılan adlandırmalar: mini, gocaoğ$\operatorname{lan}, \ldots$

4. Ses özelliklerine dayalı adlandırmalar: vizelek, çıngirye, eşek añırtlağl,...

5. Karakter özelliklerinden kaynaklı adlandırmalar: yunducu, gece guşu, tükmükçü,...

6. Cinsiyetine göre yapılan adlandırmalar: erkeç, nallı fatma, ...

7. Yapı özelliklerine dayalı adlandırmalar: sümüklü böcek, çarşak, ya$n u c ̧, \ldots$ 
8. Güzel adlandırmalar: adı denmez, canavar, gocaoğlan, ...

9. Arkaik adlandırmalar: as, kulun, elik, çıyan, toklu, yılkı, ...

10. Alınt1lardan uyarlamalar: latin, iksiri, okseyil, ...

11. Kaynă̆ı tespit edilemeyen adlandırmalar: gölbez, çökelez, ...

$\mathrm{Bu}$ veriler bize halkın ad vermedeki temel hareket noktalarını ve ad verme yöntemlerini belirlemede katkı sağlayacaktır.

\section{Kaynak Kisaltmaları:}

DS: Derleme Sözlüğü, Bkz. Komisyon (1963-1982)

MDD: Metin Dışı Derleme

SSD: Sinop’un Sualtı Dünyası, Bkz. Çelik ve Erdem (2013)

SYS: Sinop Yöresi Söz Varlığı, Bkz. Acar (2016)

\section{Kaynakça}

Acar, E. (2015). “Sinop Ağıllarında Arkaik Unsurlar Üzerine”, Sinop Illi Değerleri Sempozyumu Bildiriler Kitabl, Ankara: HTC Matbaacılık, s. 200-207.

Acar, E. (2016). Sinop Manileri (Giriş-Dil İncelemesi-Maniler-Sözlük), Ankara: Gazi Kitabevi.

-.(2016). “Sinop Yerli Ağızlarını Belirleyen Genel Özellikler”, Uluslararası Sosyal Araştırmalar Dergisi, IX, 42, 7-11.

--------.(2016). Sinop Yöresi Söz Varlı̆̆ı, (2.Basım) Ankara: Gazi Kitabevi.

--------.(2016). “Sinop ve Yöresi Ağılzlarında Mantar Adları”, Uluslararası Sosyal Araşttrmalar Dergisi, IX, 43, 7-26.

Aksan, D. (2003). Her Yönüyle Dil, Ankara: TDK Yayınları.

--------.(2006). Anlambilim Konuları ve Türkçenin Anlambilimi, Ankara: Engin Yayınevi.

--------.(2014). Türkçenin Zenginlikleri İncelikleri, Ankara: Bilgi Yayınevi. (2015). Türkçenin Sözvarlı̆̆l, Ankara: Bilgi Yayınevi.

Atalay, B. (1999). Divanü Lügati’t-Türk, Ankara: Türk Dil Kurumu Yayınları.

Çelik, S. ve Erdem, Y. (2013). Sinop'un Sualtı Dünyası, Sinop: İl Genel Meclisi Yayınları. 
Doğan, N. (2015). “Türkiye Türkçesi Söz Varlığının Yeni Renkleri Ad Bilimsel Bir İnceleme”, Dede Korkut Dergisi, IV, 7, 12-37.

Ergene, O. (2014). “Türkiye Türkçesinin Söz Varlığında Hayvan Adlarının Organ Adlarıyla ya da Vücut Bölümlerine İlişkin Adlarla Oluşturduğu Deyim Aktarması Örnekleri”, Turkish Studies, Volume 9/6, 319/365.

Erkoç, H.İ. (2015). “Divanü Lugati’t-Türk’te Vahşi Hayvanlarla İlgili Kelimeler ve Terimler”, Hacettepe Üniversitesi Türkiyat Araştırmaları Dergisi, 23, 177-208.

Guiraud, P. (1999). Anlambilim, (Çev. Berke Vardar), İstanbul: Multilingual Yayınları.

Sami, Ş. (2005). Kamûs-ı Türkî, İstanbul: Çağrı Yayınları.

Şahin, İ. (2015). Adbilim, Ankara: Pegem Akademi.

Kibar, O. (2004). Türk Kültüründe Ad Verme, Ankara: Akçă̆ Yayınları.

Kosellecki R. (2013). Kavramlar Tarihi, İstanbul: İletişim Yayınları.

Komisyon. (1963-1982). Derleme Sözlüğü I-XII, Ankara: Türk Dil Kurumu Yayınları.

Komisyon. (1977). Tarama Sözlüğ̈̈ I-VIII, Ankara: Türk Dil Kurumu Yayınları.

Yılmaz, K. (2011). “Organ Adlarının Nesnelere Aktarılmasında Dil-Zihin İlişkisi”, Turkish Studies, Volume 6/2, 1083-1092. 